Tropical Journal of Pharmaceutical Research April 2017; 16 (4): 771-779

ISSN: $1596-5996$ (print); 1596-9827 (electronic)

(C) Pharmacotherapy Group, Faculty of Pharmacy, University of Benin, Benin City, 300001 Nigeria.

All rights reserved.

Available online at http://www.tjpr.org

Original Research Article

http://dx.doi.org/10.4314/tjpr.v16i4.5

\title{
MicroRNA and gene signature of severe cutaneous drug hypersensitivity reactions reveal the role of miR-483- 5p/miR-28-5p in inflammation by targeting Granulysin gene
}

\author{
Abdallah Ahmed Elbakkoush ${ }^{1}$, Anas Khaleel ${ }^{2}$ and Chien-Tsai Liu ${ }^{{ }^{*}}$ \\ ${ }^{1}$ Graduate Institute of Biomedical Informatics, College of Medical Science and Technology, Taipei Medical University, Taipei \\ 11031, Taiwan. ${ }^{2}$ Institute of Biological Chemistry, Academia Sinica, 128 Academia Road, Section 2, Nankang District, Taipei \\ 11529, Taiwan
}

*For correspondence: Email: ctliu@tmu.edu.tw

Received: 17 January 2017

Revised accepted: 23 March 2017

\begin{abstract}
Purpose: To build a microRNA and gene signature of severe cutaneous adverse drug reactions (SCAR), including Stevens-Johnson syndrome (SJS) and toxic epidermal necrolysis (TEN).

Methods: MicroRNA expression profiles were downloaded from miRNA expression profile of patients' skin suffering from TEN using an array comprising of 372 miRNAs; download site: www.jacionline.org. The patient samples were eight TEN, ten SJS patients and twenty-two healthy individuals. A total of 192 microRNAs were found with unique expression patterns (overexpressed) in contrast with healthy skin controls and patients. Thereafter, the following databases were used for downstream analysis: geneMANIA, DIANA-miRPath version 3, DIANA-TarBase version 7.0, Ingenuity Pathway Analysis (IPA) as well as DAVID, STRING and GENECODIS online tools.

Results: Granulysin (GNLY) geneMANIA database search yielded 21 interacting genes that were 64.6 $\%$ in physical interaction, $17 \%$ in co-expression pattern. miRBD potential microRNAs that target the 21 genes were 79 miRs. Eighteen miRs overlap between the overexpressed miRs from SJS/TEN samples and the miRs targeting the 21 genes. Moreover, Ingenuity pathway analysis IPA revealed that the microRNAs were involved in inflammation.

Conclusion: Analysis of differential microRNA expressions reveals two significant DE miRs that target Granulysin (483-5p/miR-28-5p). MiR-GNLY loop interactions in hypersensitivity reactions may function as biomarkers for SCAR including SJS and TEN.
\end{abstract}

Keywords: Severe cutaneous adverse drug reactions (SCAR) Steven-Johnson Syndrome, Toxic epidermal necrolysis, Granulysin, Biomarkers, MicroRNA signature

Tropical Journal of Pharmaceutical Research is indexed by Science Citation Index (SciSearch), Scopus, International Pharmaceutical Abstract, Chemical Abstracts, Embase, Index Copernicus, EBSCO, African Index Medicus, JournalSeek, Journal Citation Reports/Science Edition, Directory of Open Access Journals (DOAJ), African Journal Online, Bioline International, Open-J-Gate and Pharmacy Abstracts

\section{INTRODUCTION}

The clinical appearances of Stevens-Johnson syndrome (SJS) and toxic epidermal necrolysis (TEN range from mild severe cutaneous adverse drug reactions (SCAR), both are rare but seldom fatal. Yet, morbidity and mortality is in rapid increase worldwide [1]. The pathogenesis of SCAR is a compound and multifactorial. It is known that drug antigen interactions, genetic background, and environmental factors might be involved [2]. SCAR are among the most significant serious skin conditions amid cutaneous drug-provoked hypersensitivity adverse conditions [3]. SJS and TEN rely on immune mediators in their hypersensitivity reactions that involve the cutaneous tissues and layers [4]. Mortality still occurs in over $5 \%$ of 
hypersensitivity adverse patients with SJS and greater than $30 \%$ of the same patients [5]. Nevertheless, the mechanisms of SJS and TEN are not fully elucidated. MicroRNAs or miRs are single stranded RNAs that are capable of posttranscriptional gene regulation via targeting their Mrna [6]. MicroRNAs are very important regulators in many human diseases, for instance, cancer [7]. Here, microRNAs are imposed as new regulators in adverse cutaneous reactions [8]. T-cell lymphocyte association with SJS and TEN was recently observed to be linked with skin reactions, in addition to the recently reported Granulysin and natural killer cells inhibitory receptors [9]. Currently, Granulysin acts as the substantial player and responsible for the dispersed keratinocyte death [10] and it has a role in cytotoxic T lymphocyte conditions [11].

In addition to Granulysin, multiple reports have revealed that numerous cytokines contributing an essential role in the apoptosis (programmed cell death) and/or the cytokine inflammations. In other reports levels of SJS and TEN cytokines were considerably greater in patient serum than healthy individuals' [12].

In the current study, Granulysin is deemed to establish core regulator and mediator along with his related/co-expressed genes and microRNAs for SJS and TEN pathogenesis. The databases and software used in this work not only attain information for DEG miRs in severe cutaneous SJS and TEN reactions, but also facilitate the approach towards discovering substantial roles in the pathogenesis of SJS and TEN.

\section{METHODS}

\section{Database and topological investigations}

\section{MicroRNAs array: differentially expressed in SCAR}

MicroRNA expression profile were downloaded from the inclusive miRNA expression profile of patients skin suffering from TEN using an array comprising of 372 miRNAs; Ichihara et al article's Online Repository at www.jacionline.org [13]. The samples were achieved from eight TEN patients, ten SJS patients with and 22 healthy volunteers. A total of 192 microRNAs were found with distinctive expressions patterns (overexpressed) in contrast between healthy skin controls and patients. Then we upload the overexpressed miRs to DIANA-miRPath v3. to obtain the significant gene list and pathways [14].

\section{Granulsyin core gene}

We loaded Granulsyin gene (GNLY) to geneMANIA database [15]; this search was important to reveal the intern actions between this core gene in SJS and TEN with other genes and microRNAs. This search yielded 21 genes that most interacting with GNLY.

\section{MicroRNAs targeting Granulsyin gene}

Characterization of the GNLY expression profiles using, DIANA-TarBase v7.0 to find the potential microRNAs targeting these genes [16].

\section{Functional annotation by DAVID web tool}

DAVID stands for: Database for Annotation, Visualization and Integrated Discovery. DAVID tool was used to annotate/confirm the function of the genes list related to Granulysin. Selection of Gene Ontology GO standings with adjusted $p$ value less than 0.05 .

\section{Network and Pathway analysis by Ingenuity Pathway Analysis IPA}

The twenty-one genes related to Granulysin were then investigated and characterized in KEGG (Kyoto Encyclopedia of Genes and Genomes) [17], Ingenuity Pathway Analysis (IPA) tools by the GENECODIS software [18]. REACTOME, is a tools for the visualization, interpretation and analysis of pathway knowledge to support basic research, genome analysis, modeling, systems biology and education [19].

\section{RESULTS}

\section{1-DIANA-miRPath 70 pathway results for the} microRNA

This search yielded more than 70 significant pathways; we chose the top ten according to $p$ Value result and number of genes targeted by the miR list loaded to DIANA-miRPath tool. All summarized in Table 1.

\section{2-GeneMANIA database results for Granulsyin gene}

Granulsyin gene (GNLY)/geneMANIA database [15], search yielded 21 genes that most interacting with GNLY.

\section{3-MicroRNAs is targeting Granulsyin gene in prediction database}

DIANA-TarBase v7.0 to confirm the microRNAs targeting these genes [16]. This search yielded around 20 miRs that target GNLY gene. Using the original database DEG miRs (192 miRs). 
Two miRs were overexpressed in SJS and TEN were among the newly identified from DIANATarBase Search. They are miR-483-5p/miR-28$5 p$. This confirm the role of both microRNAs-and their target granulysin protein.

\section{MicroRNAs targeting 21 Granulsyin-related genes}

In order to further characterize the 21 Granulsyin co-expressed genes, all genes were applied to
DIANA-TarBase to find the potential microRNA targeting them.

The miRs found to be potential regulators are shown in Table 2.

After loading the whole gene list of 21 gene names. More accurate list with more genes and microRNA were acquired from MirDB database (The target prediction database, miRDB) [20].

Table 1: DIANA-miRPath pathway results for the microRNA list

\begin{tabular}{llcc}
\hline KEGG pathway & $\boldsymbol{P}$-value & \#Genes & \#miRNAs \\
\hline Proteoglycans in cancer & $4.34 \mathrm{E}-12$ & 164 & 88 \\
Mucin type O-Glycan biosynthesis & $3.25 \mathrm{E}-11$ & 26 & 51 \\
Morphine addiction & $1.90 \mathrm{E}-09$ & 76 & 83 \\
Pathways in cancer & $7.86 \mathrm{E}-08$ & 306 & 89 \\
Axon guidance & $1.01 \mathrm{E}-07$ & 107 & 85 \\
ErbB signaling pathway & $3.16 \mathrm{E}-07$ & 77 & 81 \\
ECM-receptor interaction & $5.84 \mathrm{E}-07$ & 64 & 77 \\
Rap1 signaling pathway & $8.89 \mathrm{E}-07$ & 171 & 87 \\
N-Glycan biosynthesis & $6.03 \mathrm{E}-06$ & 38 & 62 \\
\hline
\end{tabular}

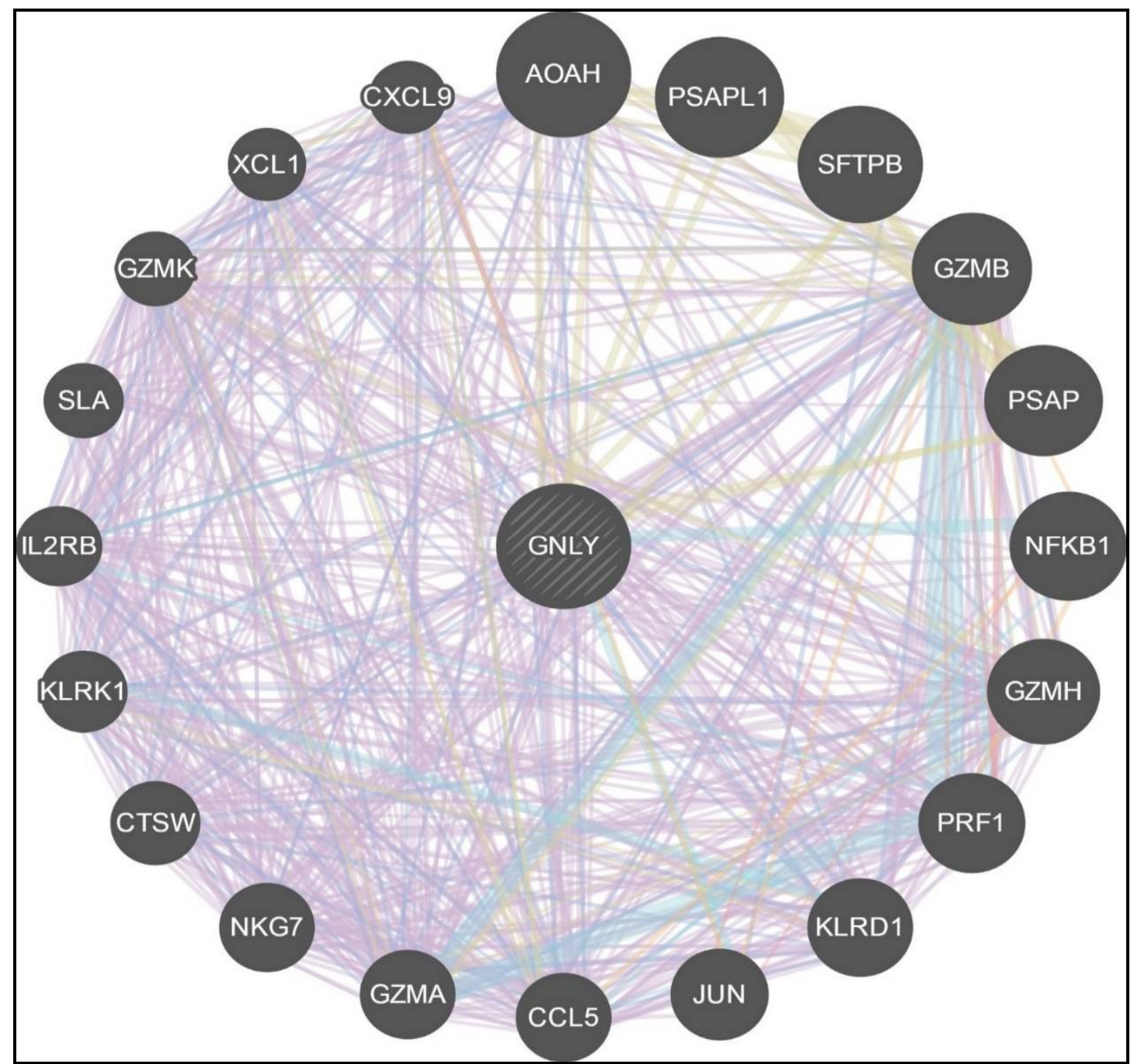

Figure 1: The twenty-one genes that interacted most with GNLY 
Table 2: DIANA-TarBase for the 21 genes interacting with Granulysin gene/GNLY

\begin{tabular}{|c|c|c|c|}
\hline Gene & miR & Score & Method \\
\hline NFKB1 & $\begin{array}{l}\text { hsa-miR-9-5p } \\
\text { hsa-miR-625-5p }\end{array}$ & $\begin{array}{l}0.967 \\
0.954\end{array}$ & Immunoprecipitation (IP) \\
\hline IL2RB (hsa) & hsa-miR-335-3p & 0.908 & Immunoprecipitation (IP) \\
\hline SLA (hsa) & hsa-miR-155-5p & 0.907 & Immunoprecipitation (IP) \\
\hline IL2RB & $\begin{array}{l}\text { hsa-miR-424-5p } \\
\text { hsa-miR-629-5p } \\
\text { hsa-miR-497-5p } \\
\text { hsa-miR-34a-5p } \\
\text { hsa-miR-449a } \\
\text { hsa-miR-186-3p } \\
\text { hsa-miR-449b-5p } \\
\text { hsa-miR-195-5p } \\
\text { hsa-miR-16-5p } \\
\text { hsa-miR-532-5p }\end{array}$ & $\begin{array}{l}0.866 \\
0.861 \\
0.825 \\
0.738 \\
0.726 \\
0.698 \\
0.672 \\
0.636 \\
0.631 \\
0.628\end{array}$ & Immunoprecipitation (IP) \\
\hline SLA & $\begin{array}{l}\text { hsa-miR-23b-3p } \\
\text { hsa-miR-23a-3p } \\
\text { hsa-miR-23c }\end{array}$ & $\begin{array}{l}0.621 \\
0.619 \\
0.618\end{array}$ & Immunoprecipitation (IP) \\
\hline$A O A H$ & $\begin{array}{l}\text { hsa-miR-199a-5p } \\
\text { hsa-miR-199b-5p }\end{array}$ & - & - \\
\hline CTSW & $\begin{array}{l}\text { hsa-miR-335-5p } \\
\text { hsa-miR-129-2-3p } \\
\text { hsa-miR-335-5p }\end{array}$ & $\begin{array}{l}- \\
- \\
-\end{array}$ & - \\
\hline PSAP & $\begin{array}{l}\text { hsa-miR-454-3p } \\
\text { hsa-miR-301a-3p } \\
\text { hsa-miR-301b } \\
\text { hsa-miR-130a-3p } \\
\text { hsa-miR-130b-3p } \\
\text { hsa-miR-3127-5p } \\
\text { hsa-miR-19b-3p } \\
\text { hsa-miR-296-3p } \\
\text { hsa-miR-19a-3p } \\
\text { hsa-miR-1226-3p }\end{array}$ & $\begin{array}{l}0.996 \\
0.980 \\
0.975 \\
0.973 \\
0.967 \\
0.821 \\
0.790 \\
0.774 \\
0.769 \\
0.739\end{array}$ & Immunoprecipitation (IP) \\
\hline JUN & $\begin{array}{l}\text { hsa-miR-200b-3p } \\
\text { hsa-miR-1277-5p }\end{array}$ & $\begin{array}{l}0.988 \\
0.967\end{array}$ & Immunoprecipitation (IP) \\
\hline GZMK & hsa-miR-335-5p & - & - \\
\hline SFTPB & hsa-miR-199a-5p & - & - \\
\hline CCL5 & hsa-miR-125a-5p & - & - \\
\hline
\end{tabular}

We scrutinized our search for microRNAs that are predicted to target the 21 genes and the overexpressed $193 \mathrm{miRs}$ and found $18 \mathrm{miRs}$ overlapping, summarized in Table 3.

\section{DAVID Functional annotation results}

The DAVID tool [21], yielded six important cluster enrichments score were as follows 5.26, 3.14, $3.04,2.85,1.87$ and 0.06 .

Most related to SJS/TEN are Chemokine signaling pathway, inflammatory response and Natural killer cell mediated cytotoxicity.

\section{Network/pathway analysis by ingenuity pathway analysis}

IPA for 21 genes related to Granulysin were then investigated and characterized in KEGG (Kyoto Encyclopedia of Genes and Genomes) [17], Ingenuity Pathway Analysis (IPA) tools by the GENECODIS software [18]. REACTOME, is a tools for the visualization, interpretation and analysis of pathway knowledge to support basic research, genome analysis, modeling, systems biology and education [19]. 
IPA results for Granulysin and the important 21 genes are shown in Figure 2.

Table 3: The 18 microRNAs validated by PCR to be overexpressed in SJS/TEN and targeting granulysin-related genes

\begin{tabular}{|c|c|c|c|c|}
\hline Ranking & $\begin{array}{l}\text { Target } \\
\text { mark }\end{array}$ & miRNA Tag & Gene & Gene full name \\
\hline 5 & 97 & miR-301b-3p & PSAP & prosaposin \\
\hline 7 & 96 & miR-19b-3p & $\overline{\mathrm{PSAP}}$ & prosaposin \\
\hline 8 & 95 & $\operatorname{miR}-92 a-1-5 p$ & $\overline{\mathrm{CXCL} 9}$ & chemokine (C-X-C motif) ligand 9 \\
\hline 12 & 94 & $\operatorname{miR}-200 c-3 p$ & JUN & jun proto-oncogene \\
\hline 18 & 88 & $\operatorname{miR}-661$ & $\underline{\text { KLRD1 }}$ & $\begin{array}{l}\text { killer cell lectin-like receptor } \\
\text { subfamily } D \text {, member } 1\end{array}$ \\
\hline 27 & 80 & miR-34a-5p & $\underline{\text { IL2RB }}$ & interleukin 2 receptor, beta \\
\hline 28 & 80 & $\operatorname{miR}-449 a$ & $\overline{\text { IL2RB }}$ & interleukin 2 receptor, beta \\
\hline 29 & 80 & $\operatorname{miR}-34 c-5 p$ & IL2RB & interleukin 2 receptor, beta \\
\hline 43 & 74 & miR-411-5p & $\underline{\text { KLRD1 }}$ & $\begin{array}{l}\text { killer cell lectin-like receptor } \\
\text { subfamily } D \text {, member } 1\end{array}$ \\
\hline 55 & 66 & $\operatorname{miR}-125 b-5 p$ & PSAPL1 & $\begin{array}{l}\text { prosaposin-like } 1 \\
\text { (gene/pseudogene) }\end{array}$ \\
\hline 62 & 65 & miR-342-5p & PSAPL1 & $\begin{array}{l}\text { prosaposin-like } 1 \\
\text { (gene/pseudogene) }\end{array}$ \\
\hline 63 & 64 & $\operatorname{miR}-145-3 p$ & $\underline{\text { GZMK }}$ & $\begin{array}{l}\text { granzyme K (granzyme 3; tryptase } \\
\text { II) }\end{array}$ \\
\hline 65 & 63 & miR-454-3p & $\underline{\text { GZMK }}$ & $\begin{array}{l}\text { granzyme K (granzyme 3; tryptase } \\
\text { II) }\end{array}$ \\
\hline 69 & 63 & $\operatorname{miR}-301 a-3 p$ & $\underline{\text { GZMK }}$ & $\begin{array}{l}\text { granzyme K (granzyme 3; tryptase } \\
\text { II) }\end{array}$ \\
\hline 70 & 62 & miR-92b-3p & $\underline{\mathrm{AOAH}}$ & acyloxyacyl hydrolase (neutrophil) \\
\hline 72 & 62 & $m i R-491-5 p$ & $\overline{\text { SFTPB }}$ & surfactant protein $\mathrm{B}$ \\
\hline 24 & 83 & miR-185-5p & $\overline{\mathrm{CXCL9}}$ & chemokine (C-X-C motif) ligand 9 \\
\hline 10 & 94 & $\mathrm{miR}-429$ & JUN & jun proto-oncogene \\
\hline
\end{tabular}

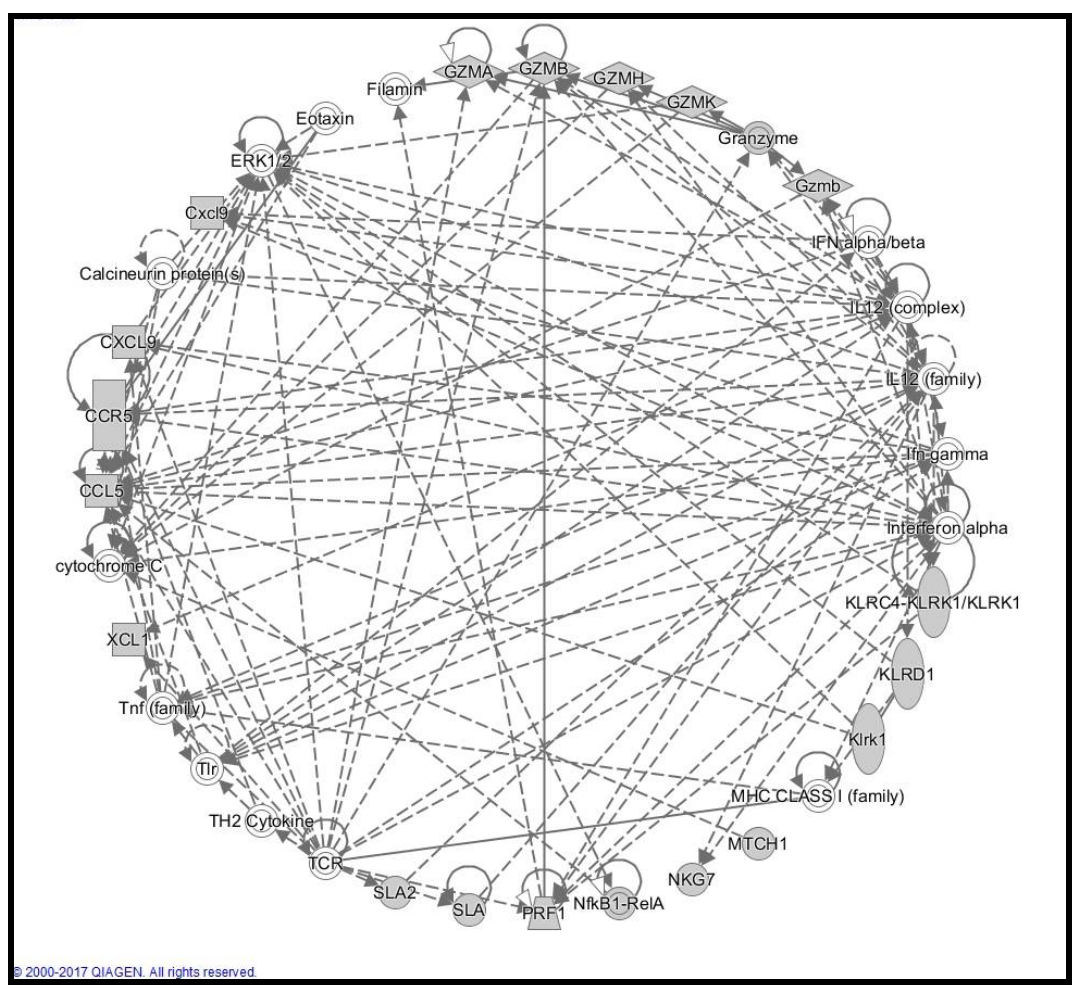

Figure 2: The confirmed 21 genes interacting with GNLY in IPA database 
In this report, several databases and web tools analyses were approached to pinpoint pathways/ network and microRNAs targeting important proteins i.e. Granulysin contributing to pathogenesis of SJS/TEN. Predominantly, Granulysin were validated to be involved in SJS and TEN before. However, never were studied from microRNA perspective. Moreover, here we prove the potential microRNA regulators of Granulysin; miR-483-5p/miR-28-5p.

REACTOME pathways [19] results for the 21 gene clusters related to Granulysin indicated that the main pathways were associated with the following:

\section{1-Toll-like Receptor 1/2 TLR1:TLR2 Cascade}

2-Toll-like Receptor 2 (TLR2) Cascade

3-Chemokine receptors bind chemokines

4-Toll-Like Receptor 4 (TLR4) Cascade

\section{5-Toll-Like Receptors Cascades.}

DAVID tool [21] results were agreeing with the other pathways analyses; IPA.

DAVID results for the 21 gene were as following:

1- Chemokine signaling pathway

2- inflammatory response i.e. SJS/TEN

3- and Natural killer cell mediated cytotoxicity

These data were generated through the use of Ingenuity Pathways Analysis, a web-delivered application that enables biologists to discover, visualize and explore therapeutically relevant networks significant to their experimental results, such as gene expression array data sets. For a detailed description of Ingenuity Pathways Analysis, visit www.Ingenuity.com.

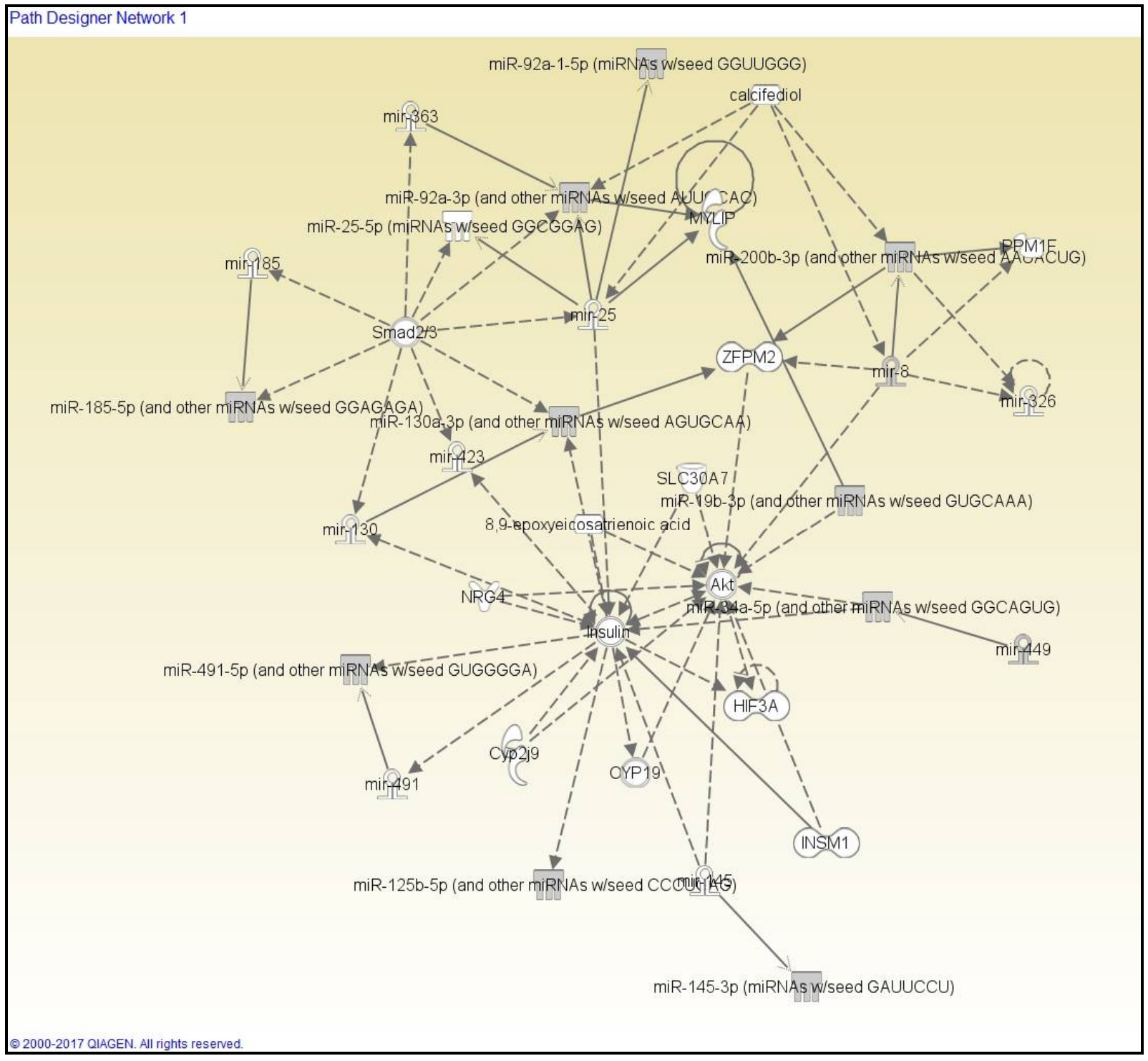

Figure 3: Genes targeted by the $18 \mathrm{miRs}$ analyzed by IPA database 


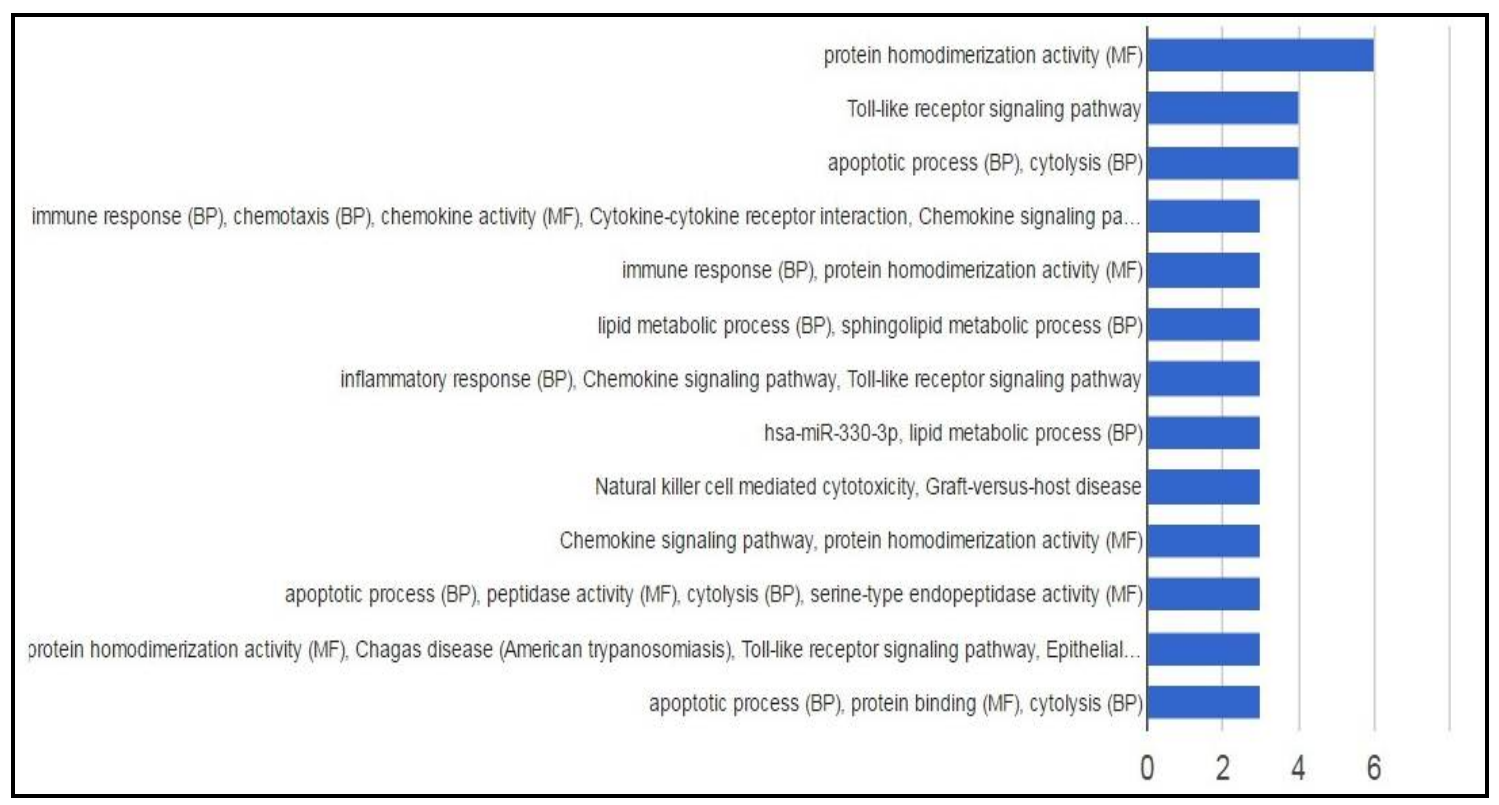

Figure 4: The twenty-on genes major pathways in IPA database

\section{DISCUSSION}

The complete genetics behind SCAR pathogenesis remains to be identified. STS and TEN, the major clinical manifestation of SCAR, continue to cause significant morbidity and mortality. In this report, databases and tools were used to investigate the differentially expressed microRNAs in SCAR.

Obtained from miRDB were 79 miRNAs predicted to target the 21 genes that interact with the Granulysin gene, the core causal gene in SCAR. Then, by overlapping the over-expressed miRNAs and potential miRNAs that target the 21 genes, a cluster of 18 miRNAs was obtained and found by Ingenuity pathway analysis (IPA) to be related to inflammation. Two significant $D E$ miRNAs targeting Granylysin (miR-483-5p/miR28-5p) were found. MiR-GNLY loop interaction in hypersensitivity may be useful biomarkers for SCAR, including SJS and TEN.

After the pathway-related microRNA clusters were identified, their genetic signature was generated to understand the pathogenesis of SJS and TEN. Our hypothesis that gene/miR signature can be applied to such a complex disease agrees with the genetic signature of HLA-B, -C, -A and -DRB1 alleles and cytochrome-P450 in a previous study [22]. Many significant pathways were also identified as hallmarks of SCAR, such as the necroptosis pathway that is mediated by annexin 1 gene which ligates to FPR1 receptor [23]. Pathways are also important signatures for SCAR. In the current report, toll-like receptor was found to be the second most important in IPA and this pathway was proved to be involved in SJS and TEN [24]. There are many reports of other pathways in SCAR-related inflammatory response [25].

In terms of drugs causing SCAR, most candidates were, Allopurinol, Carbamazepine, furosemide Erythromycin and paracetamol [26]. While, in this study, specific Granulysin gene/miR cluster could potentially serve as a biomarker for purposes of diagnosis and prognosis.

\section{CONCLUSION}

Highlighted in this report are 18 Granulysin genetargeting microRNAs that can provide insight into the pathogenesis of SCAR. Specifically, 483$5 p / m i R-28-5 p$, which are over-expressed in SCAR and validated to directly target the GNLY gene, are novel regulators of miRs that can modulate Granulysin gene expression. It is evident that the MiR-GNLY loop signature/control in hypersensitivity reactions can function as biomarkers for SCAR, including SJS and TEN. From the identified pathway-related microRNA clusters, a genetic signature is presented to understand the pathogenesis of SJS and TEN and will be highly valuable in the diagnosis and prognosis of SCAR.

\section{DECLARATIONS}

\section{Acknowledgement}


The authors would like to thank Mr Chao-Fang Chu for his kind assistance with English language Conflict of Interest

No conflict of interest associated with this work.

\section{Contribution of Authors}

The authors declare that this work was done by the authors named in this article and all liabilities pertaining to claims relating to the content of this article will be borne by them.

\section{Open Access}

This is an Open Access article that uses a funding model which does not charge readers or their institutions for access and distributed under the terms of the Creative Commons Attribution License (http://creativecommons.org/licenses/by/ 4.0) and the Budapest Open Access Initiative (http://www.budapestopenaccessinitiative.org/rea d), which permit unrestricted use, distribution, and reproduction in any medium, provided the original work is properly credited.

\section{REFERENCES}

1. Fernando SL. The management of toxic epidermal necrolysis. Australas J Dermatol. 2012; 3: 165-171.

2. Chung WH, Wang CW, Dao RL. Severe cutaneous adverse drug reactions. J Dermatol. 2016; 7: 758-166.

3. Saito N, Yoshioka N, Abe R, Qiao H, Fujita Y, Hoshina D, Suto $A$, Kase $S$, Kitaichi $N$, Ozaki M, Shimizu $H$. Stevens-Johnson syndrome/toxic epidermal necrolysis mouse model generated by using PBMCs and the skin of patients. J Allergy Clin Immunol. 2013; 131: 434-441.

4. Harr T, French LE. Stevens-Johnson syndrome and toxic epidermal necrolysis. In Adverse Cutaneous Drug Eruptions. 2012; 97: 149-166.

5. Yang MS, Kang MG, Jung JW, Song WJ, Kang HR, Cho $\mathrm{SH}$, Min KU. Clinical features and prognostic factors in severe cutaneous drug reactions. Int Arch Allergy Immunol. 2013; 162: 346-354.

6. Bartel DP. MicroRNAs: genomics, biogenesis, mechanism, and function. Cell. 2004; 116: 281-297.

7. lorio $M V$, Croce $C M$. micro RNA involvement in human cancer. Carcinogenesis. 2012; 3: 140.

8. Kopp KL, Ralfkiaer U, Nielsen BS, Gniadecki R, Woetmann A, Ødum $N$, Ralfkiaer E. Expression of miR-155 and miR-126 in situ in cutaneous T-cell lymphoma. APMIS. 2013; 121: 1020-1024.

9. Nassif A, Bensussan A, Bachot N, Bagot M, Boumsell $L$, Roujeau JC, Dorothée G, Mami-Chouaib F. Drug specific cytotoxic $T$-cells in the skin lesions of a patient with toxic epidermal necrolysis. J Investig Derm. 2002; 118: $728-733$.
10. Chung WH, Hung SI, Yang JY, Su SC, Huang SP, Wei CY, Chin SW, Chiou CC, Chu SC, Ho HC, Yang CH. Granulysin is a key mediator for disseminated keratinocyte death in Stevens-Johnson syndrome and toxic epidermal necrolysis. Nat Med. 2008; 14: 13431350.

11. Wang CW, Chung WH, Cheng YF, Ying NW, Peck K, Chen YT, Hung SI. A new nucleic acid-based agent inhibits cytotoxic $T$ lymphocyte-mediated immune disorders. J Allergy Clin Immunol. 2013; 132: 713-722.

12. Neuman MG, Cohen L, Nanau RM, Hwang PA. Genetic and immune predictors for hypersensitivity syndrome to antiepileptic drugs. TransI Res. 2012; 159: 397-406.

13. Ichihara A, Wang Z, Jinnin M, Izuno $Y$, Shimozono $N$, Yamane K, Fujisawa A, Moriya C, Fukushima S, Inoue $Y$, Ihn H. Upregulation of miR-18a-5p contributes to epidermal necrolysis in severe drug eruptions. J Allergy Clin Immunol. 2014; 133: 1065-1074.

14. Vlachos IS, Zagganas K, Paraskevopoulou MD, Georgakilas G, Karagkouni D, Vergoulis T, Dalamagas T, Hatzigeorgiou AG. DIANA-miRPath v3. 0: deciphering microRNA function with experimental support. Nucleic Acids Res. 2015: 403.

15. Zuberi K, Franz M, Rodriguez $H$, Montojo J, Lopes CT, Bader GD, Morris Q. GeneMANIA prediction server 2013 update. Nucleic Acids Res. 2013; 41: 115-122.

16. Paraskevopoulou MD, Vlachos IS, Hatzigeorgiou AG. DIANA-TarBase and DIANA Suite Tools: Studying Experimentally Supported microRNA Targets. Curr Protoc Bioinformatics. 2016: 12-14.

17. Kanehisa M, Goto S, Sato $Y$, Furumichi M, Tanabe $M$. $K E G G$ for integration and interpretation of large-scale molecular data sets. Nucleic Acids Res. 2011: gkr988.

18. Nogales-Cadenas $R$, Carmona-Saez $P$, Vazquez $M$, Vicente $C$, Yang $X$, Tirado F, Carazo JM, PascualMontano A. GeneCodis: interpreting gene lists through enrichment analysis and integration of diverse biological information. Nucleic Acids Res. 2009; 37: 317-322.

19. D'Eustachio P. Reactome knowledgebase of human biological pathways and processes. Bioinformatics for Comparative Proteomics. 2011: 49-61.

20. Wong N, Wang $X$. miRDB: an online resource for microRNA target prediction and functional annotations. Nucleic Acids Res. 2014: 1104.

21. Dennis G, Sherman BT, Hosack DA, Yang J, Gao W, Lane HC, Lempicki RA. DAVID: database for annotation, visualization, and integrated discovery. Genome Biol. 2003; 4: 60.

22. Chung WH, Hung SI, Hong HS, Hsih MS, Yang LC, Ho HC, Wu JY, Chen YT. Medical genetics: a marker for Stevens-Johnson syndrome. Nat. 2004; 428: 486.

23. Saito $N$, Qiao $H$, Yanagi $T$, Shinkuma S, Nishimura $K$, Suto A, Fujita $Y$, Suzuki S, Nomura $T$, Nakamura $H$, Nagao K. An annexin A1-FPR1 interaction contributes to necroptosis of keratinocytes in severe cutaneous adverse drug reactions. Sci Trans/ Med. 2014; 6: 245295. 
24. Ueta M. Epistatic Interactions Associated with StevensJohnson Syndrome. Cornea. 2012; 31: 57-62.

25. Yagi T, Sotozono C, Tanaka M, Fuwa M, Sekiyama E, Ueta M, Tashiro K, Kinoshita S. Cytokine storm arising on the ocular surface in a patient with Stevens-Johnson syndrome. Br J Ophthalmol. 2011; 95: 1030-1031.
26. Bellon T, Alvarez L, Mayorga C, Morel E, Torres MJ, Martín-Díaz MA, Díaz R, Radial A, Carballo M, Blanca M. Differential gene expression in drug hypersensitivity reactions: induction of alarmins in severe bullous diseases. Br J Dermatol. 2010; 162: 1014-1022. 